\title{
URUGUAY: SENDAS SEMIÓTICAS
}

\author{
Claudia González Costanzo
}

Instituto de Profesores Artigas

(Uruguay)

\section{LA SEMIÓTICA EN URUGUAY}

En Uruguay —según consta en la memoria de los profesores que, por ahora, sólo la tradición oral recoge - quien introdujo los primeros conocimientos sobre esta disciplina, fue Eugenio Coseriu. En sus cátedras de Lingüística dedicaba espacio a las aperturas y aportes que se observan en la obra de Ferdinand de Saussure, a lo que él llamaba «semiología». Fue una de las contribuciones dejadas por el profesor rumano durante su paso por este país durante parte de la década del 50 y principios de la del sesenta.

La institucionalización de la Semiótica, como disciplina autónoma se produjo en 1985, cuando se formó la Licenciatura en Ciencias de la Comunicación, dentro de la Universidad de la República Oriental del Uruguay. Lisa Block de Behar fue la fundadora de esta cátedra, a la que posteriormente reformuló bajo el encuadre de «Semiótica y Teoría 
de la Interpretación» y continúa al frente de ella. Durante esa década y la siguiente, en otra dependencia de la Universidad de la República, la Facultad de Humanidades y Ciencias de la Educación, Jorge Medina Vidal elaboró y dictó algunos cursos de Semiótica, como extensión de su cátedra de Teoría Literaria.

También en 1985, se formó la Asociación Uruguaya de Estudios Semióticos. Lisa Block de Behar y Jorge Medina Vidal fueron entonces elegidos como Presidente y Vicepresidente.

Desde 1985, la Cátedra de Semiótica (luego, Semiótica y Teoría de la Interpretación), Ciencias de la Comunicación, Universidad de la República Oriental del Uruguay, organizó y puso en marcha, numerosos seminarios, coloquios y conferencias, de los que participaron diferentes estudiosos extranjeros, con el propósito de hacer coexistir, en este país, a viva voz, la producción del conocimiento en el mundo, con su difusión aquí, a nivel universitario. Gérard Genette, Raymond Bellour, Thomas Sebeok, Jacques Derrida, Christian Metz, Haroldo de Campos, son algunos de los estudiosos que participaron en esas instancias. Una característica importante de estos encuentros es que no son ocasionales y menos aun, aleatorios. Constituyen un coherente y constante programa de actualización que, año a año incluye alrededor de una decena de actividades, funcionando con características muy similares a las de un Programa de Post-Grado.

Como ocurre a lo largo y ancho del planeta, existen diferentes análisis de enfoque semiótico o que incluyen nociones de la Semiótica, diseminados aquí y allá. Existen, también, como en otras partes del mundo, apuntes en los que se delizan elementos semióticos dentro de trabajos que, en virtud de su objeto de estudio y su enfoque, son comunicacionistas.

Pero también hay una serie de desarrollos teóricos, gracias a los cuales, en el área de la Semiótica, Uruguay no es sólo un país de recepción, sino que ha podido ofrecer elementos para el enriquecimiento de la disciplina. Es en los escritos de Lisa Block de Behar, donde debemos buscarlos.

\section{LA SEMIÓTICA DESDE URUGUAY}

Los trabajos de Lisa Block de Behar incluyen la elaboración de nociones teóricas, así como propuestas metodológicas de análisis y lo 
que usualmente se considera aplicación de esos herramentales, al discurso verbal, al literario y al cine. El desarrollo conjunto de estos tres aspectos en cada uno de sus estudios conlleva la coherencia interna de tales trabajos: prueba la funcionalidad práctica de la teoría expuesta, al tiempo que exhibe los fundamentos de sus observaciones.

Las mencionadas clasificaciones podrían ayudar a organizar un resumen de algunos de sus aportes pero, luego de planteadas, deben ser dejadas a un lado si no se quiere traicionar la opción epistemológica de la autora.

\section{Una opción epistemológica}

Por un lado, podría vérsela como una búsqueda permanente a través de la pregunta. No hay principio teórico ni concepto que no sea cuestionado en sus textos, en el doble sentido de la exploración y la duda. La misma postura interrogante observa ante sus objetos de estudio, en los que siempre encuentra oportunidades de nuevas formulaciones teóricas o profundizaciones de nociones planteadas en estudios precedentes. Podría decirse que generalmente trabaja en las fisuras que se abren en los sistemas teóricos o entre objeto de estudio y teoría, tejiendo pasadizos que permiten unir lo que aparecía como desarticulado. En esos pasadizos, teoría, lenguaje científico, lenguaje poético, ficción, conjetura, se funden, constituyendo una dimensión epistemológica que resiste (y rechaza) las clasificaciones.

De otro lado, otras clasificaciones se diluyen también, y otros vasos comunicantes se entretejen. Son los que conectan diferentes disciplinas. Lo más frecuente es que un mismo objeto de estudio sea analizado desde una perspectiva semiótica, conjuntamente con una lingüística, con otra emanada de la Teoría Literaria, otra hermenéutica... Esto evita las parcelaciones a las que necesariamente se somete el conocimiento cuando el estudio se circunscribe a las posibilidades que brinda una única disciplina. También enriquece a cada una de las ramas del conocimiento concurrentes en un análisis, puesto que muchas veces la autora cruza (y así motiva la procreación) dos conceptos provenientes de disciplinas diferentes, de los que surge un tercero (la procreación antedicha) que incrementa a la vez el acervo de los dos o más dominios del conocimiento combinados. 
La conjunción de todo esto se traduce en una relación con los objetos de estudio diferente a la dominante en la ciencia actual. En los trabajos de esta autora la mirada del analista no es exterior, ajena y distante a su objeto y el recorrido de esa mirada no es secuencial, lineal y progresivo. La mirada del analista, en estos trabajos, efectúa una suerte de viaje interno por su objeto, por sus contextos, un desplazamiento intra e inter-objetal, unido a una visión circunvaladora, próxima a una perspectiva cubista, pero asociada a un enfoque desconstructivo.

Puede observarse la preferencia por el estudio de unidades mínimas del discurso y el rastreo de cómo resultan conformadoras no sólo de un discurso determinado sino, muchas veces, de una visión del mundo que el autor o realizador esta proponiendo.

Apenas como indicios de sus estudios, presentamos en las siguientes líneas, una escueta síntesis de algunas de las más importantes nociones trabajadas por Lisa Block de Behar.

\section{Movimientos anafóricos}

La anáfora es una figura que ha concentrado la atención de la autora, desde sus primeros trabajos publicados, en $1969^{1}$. Desde entonces se ha constituido en una preocupación recurrente, como foco de diferentes nociones teóricas; un despliegue teórico que alberga la polisemia contradictoria de la palabra «foco». En ocasiones, la anáfora ha sido el núcleo de los análisis; otras veces, ha constituido el elemento externo al objeto de estudio tratado que permite iluminar aristas aún no exploradas en el objeto en cuestión.

Este privilegio de la anáfora está ligado a los fundamentos más esenciales de sus teorías. En primer lugar, es una de esas unidades elementales del discurso, a que hacíamos referencia. En segundo lugar, tal como lo señala la autora - desarrollando y encontrando nuevos alcances para las consideraciones de Karl Bühler ý Roman Jakobson-, la anáfora es una figura de intermediación. Una figura que pertenece a la

1 Análisis de un lenguaje en crisis (Block de Behar, 1969). 
vez a campos del lenguaje ${ }^{2}$ que para las diferentes teorías vigentes constituyen entidades separadas y cerradas sobre sí mismas. La anáfora pertenece a la vez al campo mostrativo y al simbólico del lenguaje; tiene un referente (externo al discurso por definición) y una función deíctica que tiene la peculiaridad de señalar partes del discurso. La autora profundiza en las derivaciones de esta doble condición de la anáfora, hasta observar cómo el análisis de esta figura permite cuestionar la noción de representación y la de código. Descubre cuando menos, zonas de la comunicación en las que no rige la duplicación entre realidad y un sistema abstracto - más o menos convencional- paralelo a esa realidad y que es su imperfecta y humana traducción. Zonas de pasaje, vasos comunicantes, en los que el lenguaje representa y a la vez se presenta (es, también, objeto), al tiempo que la realidad representada ofrece también mecanismos de representación inmanentes a ella.

Como es figura de intermediación, el estudio de la anáfora también tiende a disolver las fronteras entre los que han sido considerados tipos de discursos diferentes. Una de las consecuencias del célebre artículo de Roman Jakobson sobre la metáfora y la metonimia es que consagraba, desde el seno mismo de los estudios lingüísticos y retóricos, la irreconciliable separación entre verdad y fantasía: la metonimia era presentada como la figura estructurante de los discursos que tienen por referente la verdad (los científicos) y la metáfora la de los que tienen como referente lo imaginario (la poesía). Es verdad que los análisis de Jakobson implican otras complicaciones, relativas a la metonimia y la narración, por ejemplo, pero no son esos aspectos de su trabajo los que aquí nos interesa recordar. Lo que interesa aquí es que según las consideraciones de Lisa Block de Behar (1990: 106), la anáfora comparte características definitorias de la metáfora y de la metonimia; y que al ser el componente esencial que da a un discurso su unidad, estando más próxima a la ubicuidad en las construcciones discursivas que la metonimia y la metáfora, al presentar rasgos de una y otra, resulta que a través de la anáfora todo discurso es metafórico y metonímico a la vez. Luego, todo discurso tiene por referente parte de la verdad y parte de lo imaginario.

Son nociones un tanto perturbadoras, cuya observación queda habilitada cuando se mira en los espacios vacíos, cuando la mirada se dirige a lo que «está entre»: «Entre tantas oposiciones suspendidas, y sin

${ }^{2}$ Lenguaje verbal, en principio, puesto que los estudios de la anáfora se iniciaron en relación al lenguaje verbal, pero, como se verá, esto se traslada a lenguajes, o sistemas de codificación no verbales. 
descartar las relaciones problemáticas que se establecen entre la realidad y la ficción, entre una visión y otras visiones, la imaginación anafórica da lugar a un nuevo realismo, un realismo cada vez más sospechoso, un entrerrealismo más bien donde no sorprende que el director desee o decida permanecer en el medio, entre intérpretes, entre periodistas, quienes haciendo un interview o una intervista, cumplen su intermediación entre dos lenguas» (Block de Behar, 1990: 119).

En el lector, el efecto que produce la anáfora (también la catáfora) es el de movimiento: cada repetición lo traslada hacia adelante y hacia atrás en el texto que lee, en la comunicación que escucha, en el filme que mira. Esta condición de «estar entre» que Lisa Block de Behar subraya hace que esos traslados se multipliquen, de la realidad a la ficción, a la ciencia, al diálogo. Como la palabra en el texto, el lectorespectador está fijado en un único lugar, mientras lee o mira y al mismo tiempo, las derivaciones anafóricas habilitan su multi-localización.

Por su parte el cine, como lo dice el nombre que triunfó para designarlo, es movimiento y no biógrafo. Un movimiento cuyas articulaciones anafóricas la autora ahonda, siguiendo las búsquedas de Metz; pero en el que destaca la potencialidad significativa del silencio. Destaca el movimiento anafórico que ya no reside en la palabra, sino en su ausencia (Block de Behar, 1990: 101 y siguientes). Varias otras formas de relación entre palabra e imagen son por ella abordadas a lo largo de sus escritos.

Como la autora lo señala, al ser una repetición, la anáfora es una figura de semejanza; nada es más semejante que lo igual. Pero ella apunta también: «Se había dicho antes que la repetición es el fenómeno cultural más importante, pero hace falta agregar que esta importancia procede del hecho, contradictorio, de que una verdadera repetición no existe» (Block de Behar, 1984: 106). La anáfora es una semejanza, una repetición que difiere. Cada vez que se reitera la misma palabra o la misma expresión se vincula a significaciones diferentes, al tiempo que mantiene las anteriores.

Un fenómeno cercano a éste resulta de leer como silepsis diferentes polisemias. En este caso ya no hay vínculo, sino impregnación: la autora ha mostrado cómo diferentes palabras polisémicas lucen la conjunción de varias de sus significaciones en un mismo discurso. Por esta vía, a la distancia, de un texto a otro, de uno a otro discurso, entre filmes, hay un movimiento anafórico también: cada vez que una de esas palabras se repite comporta consigo todos los significados que ha 
tenido. Otra vez se multiplican los traslados pero, en esta perspectiva, los observamos entre enunciados y entre sentidos. El hallazgo y uso de cadenas de silepsis constituye un procedimiento totalmente científico, apoyado en las más rigurosas nociones de la Lingüística, del que resulta, lo que durante muchos años se vio como opuesto a la ciencia: un lenguaje poético. Pensar en superposiciones polisémicas, es pensar poéticamente con rigor científico. Otra forma del «estar entre».

A su vez, ésas que me permito designar como 'superposiciones polisémicas' han constituido la clave de diferentes nociones o de algunos desarrollos teóricos. «Cita», «teoría», «lugar común», son algunas de las expresiones que, a través de la silepsis, la autora ha rescatado como nociones teóricas. «Cordón», «figura», son algunas de las que, mediante similar procedimiento, ha convertido en clave de desarrollos teóricos. Un sólo ejemplo bastaría para ilustrar el procedimiento. Pero tanto en su «teoría de los cordones» ${ }^{3}$ como en sus abordajes intra (más que inter) disciplinarios de las figuras (retóricas, sólo en principio), además de ver cómo aquella noción se vuelve procedimiento de análisis, se registran nuevos aportes teóricos, sobre los que entendemos necesario hacer alguna anotación.

La autora recuerda que el cordón es un elemento que separa realidad y ficción, espectáculo y espectador. Reiterémoslo: tradicionalmente los requisitos básicos para que la ficción pueda desenvolverse son que se delimite claramente el espacio (los casos más claros son los de las exposiciones de arte o el teatro) que le está reservado y que ese espacio no sea transgredido. No sobrará tener presente que todos los juegos artísticos y críticos que trabajan con esa transgresión se apoyan sobre la acendrada convicción de que se trata de eso, de transgresiones, lo que en realidad refuerza la observación de la necesidad de estos cordones de separación para que el artificio ficcional pueda existir.

La polisemia de la palabra cordón, leída en esa dinámica de conjunciones que es propia de Lisa Block de Behar, permite observar que al tiempo que separa, el cordón, une. Por esta vía, otra vez, mundos considerados usualmente como ajenos, se descubren en íntima conexión; otra vez se observan zonas de uniones entre diferentes zonas del saber; otra vez, los componentes más íntimos, más ele-

${ }^{3}$ Revista Degrés 31, Bruselas, 1982. Retomada en varios estudios posteriores. Véase especialmente, Al margen de Borges (Block de Behar, 1987: 126 y ss). 
mentales de lo existente, rehuyen las clasificaciones: «De la misma manera que las "metalepsis narrativas" de las que habla Gérard Genette, los cordones exponen "las fronteras en movimiento", las problemáticas inserciones de la narración en otro plano, el lugar donde (se) juegan su interioridad y exterioridad, su ficción y verdad» (Block de Behar, 1987: 126).

Varios misterios de la Literatura, comienzan a aclararse, merced a la teorías de los cordones: «Por su intermediación suelen ocurrir los deslizamientos elusivos y las desconcertantes reciprocidades que desfiguran a los personajes de Borges (...) También por medio del mismo expediente quedan cuestionadas las atribuciones de los narradores y narratarios de la literatura más tradicional» (Block de Behar, 1987: 127).

El análisis de la polisemia de «figura» dio varios estudios sobre Laforgue ${ }^{4}$ que en principio rastrearon las coincidencias que en el escritor se observan, entre figura-personaje y figura retórica. Al releer desde la Lingüística, no sólo la profusión retórica de Laforgue, sino toda su escritura, Lisa Block de Behar configuró, una nueva noción, posteriormente contrastada con la obra de diferentes escritores, y cuya verificación, como uno de los «universales» del lenguaje está próxima: la intraducción. Por la importancia de sus alcances, merecerá en estas líneas, una sección aparte. Por otros caminos esa polisemia habilitó la reunión de nociones retóricas, geométricas, geográficas y tecnológicas, en función de las cuales, la autora planteó una elaboración semiótica (tributaria de Peirce) del análisis hermenéutico ${ }^{5}$. Por similares razones, también será tratada en su propia sección, como la anterior. Las consideraciones formuladas por la autora sobre la crisis de la representación y la pérdida del referente, así como sobre la semántica del nombre propio, también exigen un tratamiento particular.

4 Jules Laforgue o las metáforas del desplazamiento (Block de Behar, 1987a). «Jules Laforque», una "figura" uruguaya (Anotaciones biográficas y poéticas para el estudio de una figura retórica necesaria), comunicación presentada en el Primer Congreso de ABRALIC (Asociación Brasilera de Literatura Comparada), 1988 y publicada luego en Dos medios entre dos medios: sobre la representación y sus dualidades, 1990 y en A Rhetoric of Silence and Other Selected Writings, 1995.

5 «El espectro semiótico en "La muerte y la brújula" de Jorge Luis Borges», comunicación presentada en oportunidad de la creación del Instituto Internacional de Semiótica (ISI) que tuvo lugar en Imatra, Finlandia, el 25 de julio de 1988. El texto se publicó en Dos medios entre dos medios: sobre la representación y sus dualidades, 1990 y en A Rhetoric of Silence and Other Selected Writings, 1995. 


\section{Desreferencialización}

Al estudiar la anáfora, la autora lleva nuestra atención a lo que queda entre, a lo que media entre dos. Y descubre que en vez de una función de segundo orden, de instrumento, lo «que queda entre» es lo que impone su existencia a los elementos entre los que media: la anáfora sobresale en relación al discurso que articula; los medios, los discursos e imágenes mediáticas, sustituyen al referente.

No es la primera vez que se estudia este fenómeno, es decir, el fenómeno de que la referencia sea una realidad, un objeto existente, en tanto los referentes, los hechos y objetos tangibles, desaparecen. No es la primera vez que se observa que tenemos más relaciones con referencias que con referentes que, el conocimiento de cada individuo está hecho, sobre todo, de una combinación de referencias. En la obra de muchos estudiosos de las últimas décadas, se trata de una obsesión aglutinante: no tenemos más que lenguaje. Entre los caminos que siguen las búsquedas animadas por esa obsesión, los caminos anafóricos que nos propone la autora, constituyen, en el recorrido, y en el tejido de interrelaciones, una alternativa que anuncia terrenos a explorar.

Atendiendo esas relaciones entre Literatura e Historia, entre verdad y ficcción -que tanto le preocupan- Lisa Block de Behar se detiene en las vicisitudes y estrategias de solución que enfrenta y despliega el lector. Solo de paso anotemos que ha planteado una tesis, retomada por ella insistentemente en nuevos desarrolllos, sobre el lugar y función de la lectura en las relaciones y sistemas de la comunicación ${ }^{6}$. En uno de esos retornos, apunta: «Aunque no quede registrado, es el lector quien intenta realizar la convergencia transhistórica, por medio de un recorrido anafórico, un salto atrás que no lo aparta de su presente, encabalgando lo literal y lo literario, contrayendo lo ya dicho y lo no dicho, la repetición y el silencio.» (Block de Behar, 1987: 102). En tal oportunidad, el objeto de su análisis era la problemática que se registra en la representación cuando el referente desapareció, es decir, casi siempre, aunque no sean tan frecuentes las observaciones de los estudiosos

6 Una retórica del silencio (Block de Behar, 1984). En su versión francesa, esta obra fue presentada como tesis de Doctorado en Linguística, en L'École des Hautes Études en Sciences Sociales de Paris, al Profesor Gerard Genette. La versión española, publicada por Siglo XXI, Buenos Aires, en 1984 y reimpresa en 1994, recibió en México el Premio Xavier Villaurrutia al Ensayo Literario, en 1984. La versión en inglés fue publicada por Mouton de Gruyter, Berlín-New York en 1995. 
sobre esta propiedad de casi todas las representaciones. Todo el discurso histórico, por ejemplo y, como ella lo estudia, todas las alusiones e indicaciones históricas de los textos literarios, constituyen conjuntos de referencias cuyos referentes han desaparecido.

En su lugar, la autora observa, que esta reducción a cero del referente va acompañada de una multiplicación de la representación: «la verdad es una relación intelectual que establece coherencia entre la representación que concibe, momentáneamente y sin dejar rastros, el lector, y la representación que la obra propone indefinidamente - tanto por infinita, ilimitada, como por incierta e imprecisa» (Block de Behar, 1987: 101).

$\mathrm{Y}$, vuelta al lector (el movimiento teórico es tan anafórico como el de la lectura y el del texto), la significación y la interpretación se hacen también, ilimitadas, mientras la verdad se desdibuja. Vuelta, entonces, a Peirce: «Más vale mantener el enigma, continuar la búsqueda, aunque conste que así la verdad se escurra en la 'semiosis ilimitada' de Peirce, ya que esa fuga no es una falla, una falta, sino su fatalidad: su manera de ser necesaria» (Block de Behar, 1987: 94).

Así, también la representación de la representación se ha multiplicado; esto es, se han ido multiplicando las disciplinas del conocimiento y las tendencias teóricas y metodológicas dentro de ellas. Tal vez no por casualidad, la Semiótica replique el binarismo representación/realidad, ofreciendo el tradicional esquema binario de sus dos grandes fuentes. Ante esto, la autora nos devuelve al objeto de estudio, al lenguaje; si el referente se desrealiza, mucho más esa representación en segundo grado, que constituye un dogma teórico (una noción que pasa de la episteme a la sentencia). De nuevo, el resultado de las diferentes combinaciones es uno, el lenguaje: «Me parece oportuno sacar partido de la polisemia de la palabra medio en español (Lat. medius) con la intención de establecer relaciones entre fracciones y unidades: Dos medios entre dos medios ${ }^{7}$ da como resultado tres unidades o tres veces una unidad singular: $2 / 2$ dividido entre $2 / 2=1$, o simplificando, $1 / 1=1$, y por medio de esta operación elemental, es posible no negar la tradición binaria de Saussure ni la triádica tradición de Peirce» (Block de Behar, 1994: 122).

A propósito de estas consideraciones y a través de esas superposiciones polisémicas tan suyas, y que, en este caso, ha sabido ver en

7 Mediante nota a pie de página, la autora se refiere al título del libro y al propio libro de 1990, del que se han hecho algunas menciones en líneas precedentes. 
nuestro español, la autora va al encuentro de Thomas Sebeok en la cita: «En términos de Sebeok, ya en las conclusiones de su libro Semiotics in the United States, cuando afirma 'Repito que la misión primordial de la semiótica es y será la de mediar entre la realidad y la ilusión' (...)» (Block de Behar, 1990: 123). Según esto, como lenguaje que analiza el lenguaje, la Semiótica necesitará privilegiar siempre su condición primera, la de ser un lenguaje, para no verse presa de la desreferencialización que ha permitido mostrar.

\section{La semantización del nombre propio}

Un nuevo movimiento bascular, promovido por esa actitud siempre interrogante ante lo preestablecido, siempre inquiriendo por la posible co-presencia de dos elementos contrarios, como alternativa a la usual mirada unidireccional, la lleva a focalizar su atención en un tipo de palabra de la cual la Lingúística se ha ocupado, fundamentalmente, para estudiar sus relaciones con sus referentes: el nombre propio. "Como ocurre con la mayor parte de los nombres propios, son tantos los motivos que coinciden al ponerlos, tantos otros que se conjeturan al suponerlos que, aunque los lingüistas defiendan el vacío conceptual de los nombre propios, por todos estos motivos el nombre significa en forma diferente, designando cualquier objeto sin que cuenten las propiedades que el objeto presenta, pero significa» (Block de Behar, 1990: 96).

En cierta forma, la semantización, la presencia de significados en los nombres (propios), es una forma de desreferencialización. No es la problemática de la representación puesta de manifiesto ante la desaparición de un referente, lo analizado en este caso. El caso de los nombres propios, interesa en el marco de esta teoría porque en el análisis linguiístico tradicional, constituye un fundamento que avala la tesis de que el lenguaje es un sistema de correspondencias convencionales. A la inversa, en tanto se toma en cuenta que los nombres propios tienen las mismas propiedades que todas las otras palabras que pertenecen al campo simbólico del lenguaje (aunque tengan, además una relación con sus referentes que los agrupa en un subconjunto relativamente autónomo), se ofrece un aporte con la tesis de la motivación del símbolo. Pero hay una forma de la desreferencialización cuando la importancia del referente se debilita, cuando se observa que estas palabras 
son tales, que tienen significación propia, con independencia de los diferentes referentes a cuya designación se apliquen.

Con su antecedente confeso en Barthes ${ }^{8}$, estos análisis de la semántica del nombre propio se extienden a lo largo y a lo ancho de los escritos de la autora. Su investigación se proyecta desde la ficción. La proyección se irradia desde los nombres de personajes literarios, en los que la motivación es más visible (o más fácilmente aceptable dentro de nuestras pautas de verosimilitud). Abarca los nombres de los personajes de textos sagrados (en los que el sistema de creencias apoya, también, esa motivación). Se extiende a nombres de escritores que han hecho de la semantización de los nombres de sus personajes una clave de su cosmovisión literaria (destaca, en los análisis de Lisa Block de Behar, el de Jorge Luis Borges); escritores que por esta vía, unida a otros procedimientos coincidentes, se han colocado a sí mismos, y a su propio nombre, en esa zona de frontera entre ficción realidad, entre motivación y convención, en la zona mediática, anafórica, que comienza a aceptarse como más real que la zona habitada bajo la señal «referente».

En los escritos de la autora, ha merecido un capítulo aparte, el uso e implicaciones, así como los diferentes procesos lingüísticos y semióticos, que se registran en la publicidad en torno a este fenómeno de semantización del nombre propio. En su libro El lenguaje de la publicidad ${ }^{9}$, plantea que el problema de los nombres, el problema de las marcas (en los sentidos semiótico y publicitario del término) es el núcleo del lenguaje y del fenómeno publicitarios.

\section{Introducción}

En líneas anteriores anotábamos que esta perspectiva de mirar «entre» y analizar lo que «está entre», guarda relación, más que con el prefijo «inter» (tan al uso), con el prefijo «intra». El elemento mediador es visto como el más intimamente enraizado en las profundidades de las realidades mediadas. Un fenómeno de la misma naturaleza ha sido reconocido por la autora, cuando se ocupó de investigar las relaciones entre lenguas.

8 Roland Barthes, «Los nombres de Proust».

9 Block de Behar (1973). 
Mas allá de la conocida relación de «interlangue», ligada fundamentalmente a la noción de influencias de unas lenguas en otras (de unas culturas en otras) y que en más de una forma privilegia la mirada de lo exterior, en materia de lenguaje, la autora ha acuñado el concepto de «intraducción».

Este concepto incluye la observación de rastros de unas lenguas en otras. Pero es, a la vez, la amalgama de dos nociones que, en apariencia, se oponen. Una proviene de la constatación de la imposibilidad de una traducción literal; por esta vía, el concepto se acerca a la teoría de «transcreación», de Haroldo de Campos. La otra fue observada por la autora, en principio, en la escritura de Laforgue y luego en la de Borges, escritores que por su circunstancia autobiográfica navegaron siempre entre su lengua (paterna, para el segundo, paterna y materna para el primero) y la de sus países de nacimiento; al presente, la investigación va extendiéndose hacia escrituras no fonéticas. Se trata de palabras y construcciones lingüísticas, cuya significación (incluida la significación de su sonoridad) sólo puede comprenderse cuando, a la vez se las lee en más de una lengua; las denotaciones y asociaciones que la palabra o la construcción comporta en varias lenguas se combinan en estos textos: «De la misma manera que la ceguera de sus ojos sin vida le anticipa la pre-visión de su vida sin tiempo, le devuelve paradójicamente el lenguaje de sus antepasados, un lenguaje de hierro que funde, a través de sus idiomas y sus diferencias particulares, la ironía que multiplica los sentidos hasta colmar un mismo signo, donde empieza el infinito de la significación» (Block de Behar, 1994: 94) ${ }^{10}$.

Por una vía, el concepto se nutre de una noción que tiende a fortalecer la idea de fronteras infranqueables entre lenguas; por la otra, esas fronteras se reducen a meros artificios. Entre opuestos, la intraducción da cuenta de las diferencias idiomáticas y las trasciende.

Este concepto constituye un aporte a los análisis literarios. Pero sus alcances linguísticos lo enlazan con las búsquedas de la Urschprache, en una definición que se aparta de los derroteros del siglo XIX y privilegia lo que en ella hay de inalcazable.

10 La primera versión de esa conferencia, «Borges, a Blind Seer», fue presentada por la autora cuando se le designó «fellow» del Institute for Advanced Study, Universidad de Indiana, Bloomington e Indianápolis. 


\section{Hermenéutica y Semiótica}

Como hemos visto, en el abordaje de Lisa Block de Behar la ficción es la más prolífica fuente de teoría. Coherencias que se debe quien ha formulado la teoría apuntada sobre «los cordones».

Así, es a partir de una lectura de «La muerte y la brújula» (ver nota 5), que encontramos una de las formulaciones más precisas acerca de cordones que ligan Hermenéutica y Semiótica: «El cuento redunda en un ejercicio alegórico múltiple, una alegoría de la alegoría que es toda lectura literaria, una práctica hermenéutica donde se entrecruzan las funciones retóricas, las estrategias tropológicas como las operaciones de persuación y seducción que la lectura involucra» (Block de Behar, 1990: 60).

En «La muerte y la brújula», el emergente de la opción hermenéutica es el protagonista del cuento. Su razonamiento hermenéutico fracasa, con lo cual fracasaría también el lector si se limitara a identificarse con Elias Lönrot y se contentara con procedimientos hermenéuticos. Como sucede con casi toda la obra de Borges, el cuento puede verse en una dimensión alegórica y así observar que la ficción es sólo un terreno provisoriamente acordonado para referirse a la ciencia y que son las limitaciones de la Hermenéutica, las que conducirían al fracaso del conocimiento, si las búsquedas del saber se limitaran a las posibilidades de esa disciplina. Una opción semiótica, la abducción, sirve a socorrer al lector, a permitirle ver más que el protagonista: «Por medio de su cuento, Borges hace compatibles varios sentidos de la abducción, o varios sentidos a la vez, ya que seguramente le interesa combinarlos simbólicamente» (Block de Behar, 1990: 53).

\section{Desde Uruguay ...}

Los indicios parecen indicar un rumbo que desconfía de la segmentación (metonimias, clasificaciones) en la ciencia, y que se orienta hacia una trascendencia mediática. 


\section{Bibliografía}

BARTHES, ROLAND, (1973). El grado cero de la escritura y otros ensayos. Buenos Aires: Siglo XXI Editores.

BLOCK DE BEHAR, LISA (1969). Análisis de un lenguaje en crisis. Montevideo: Nuestra Tierra.

- (1973). El lenguaje de la publicida. Buenos Aires: Siglo XXI Editores.

- (1984). Una retórica del silencio. Buenos Aires: Siglo XXI Editores.

- (1987a). Laforgue o las metáforas del desplazamiento. Montevideo: Ministerio de Educación y Cultura.

- (1987b). Al margen de Borges. Buenos Aires: Siglo XXI Editores.

- (1990). Dos medios entre dos medios. Buenos Aires: Siglo XXI Editores.

- (1994). Una palabra propiamente dicha. Buenos Aires: Siglo XXI Editores.

- (1995). A Rhetoric of Silence and Other Selected Writings. BerlínNew York: Mouton de Gruyter.

BORGES, JORGE LuIS (1974). Obras Completas. Buenos Aires: Emecé Editores.

BÜLHER, KARL (1967). Teoría del lenguaje. Madrid: Revista de Occidente.

GENETTE, GÉRARD (1972). Figures 111. París: Seuil.

JAKOBSON, ROMAN (1963). Essais de linguistique Générale, trad. Nicolás Ruwet. París: Minuit.

Metz, Christian (1984). Le signifiant imaginaire. París: Chritian Borgois.

PeIRCE, Ch. S., (1931-1958). Collected papers. Harvard University Press.

SAUSSURE, (1916). Cours de linguistique générale. Ginebra: Payot.

Sebeok, Thomas, (1991). Semiotics in the United States. Bloomington: Indiana University Press. 